\title{
LESSONS FROM THE LEBANESE SOCIAL ENTREPRENEURSHIP ECOSYSTEM
}


Social enterprises in Lebanon operate under a weak regulatory framework and face a number of operational and policy-level challenges. Gaps in services mean it is difficult for them to function effectively, and there is a need for a coordination platform that can facilitate improvements in the social enterprise ecosystem. The needs of social enterprises are unique and should be addressed differently to those of for-profit businesses. This paper draws on a landscape study conducted by Beyond Relief and Development for Oxfam's MedUP! Promoting Social Entrepreneurship in the Mediterranean Region project. It identifies the barriers social enterprises in Lebanon face and makes recommendations on how the environment in which they operate can be improved.

(C) Oxfam International March 2020

This case study was written by Zeina Maroush, Hovig Wannis and Ghinwa Haidar (Oxfam), and Tania Ayoub (Beyond Relief and Development). Oxfam acknowledges the assistance of the livelihoods programme and partners in its production. It is part of a series of papers written to inform public debate on development and humanitarian policy issues.

For further information on the issues raised in this paper please email Hovig Wannis (hwannis@oxfam.org.uk) and Zeina Maroush (zmaroush@oxfam.org.uk).

This publication is copyright but the text may be used free of charge for the purposes of advocacy, campaigning, education, and research, provided that the source is acknowledged in full. The copyright holder requests that all such use be registered with them for impact assessment purposes. For copying in any other circumstances, or for re-use in other publications, or for translation or adaptation, permission must be secured and a fee may be charged. Email policyandpractice@oxfam.org.uk.

The information in this publication is correct at the time of going to press.

Published by Oxfam GB for Oxfam International under ISBN 978-1-78748-583-9 in March 2020.

DOI: $10.21201 / 2020.5839$

Oxfam GB, Oxfam House, John Smith Drive, Cowley, Oxford, OX4 2JY, UK. 


\section{LEBANON'S SOCIO-POLITICAL CONTEXT AND THE SYRIAN CRISIS}

Lebanon's political and economic system has historically given rise to high levels of inequality, with geographical and social factors also playing a significant role. ${ }^{1}$ Before the Syrian crisis, the country was facing problems of high rates of unemployment and poverty, weak public services and corruption. ${ }^{2}$ The crisis has had profound humanitarian, socio-economic and political impacts on Lebanon, ${ }^{3}$ and in 2019 the economic situation took a significant downturn. According to the Lebanon Crisis Response Plan (LCRP), unemployment and high levels of informal labour were already serious problems pre-crisis, ${ }^{4}$ with the World Bank suggesting that the Lebanese economy would need to create six times as many jobs as it does now just to absorb regular market entrants. ${ }^{5}$ Prior to the crisis, a 2013 World Bank enterprise study looking at registered companies in Lebanon found that the main obstacle hampering businesses of all sizes was political instability. ${ }^{6}$ The capacity of vulnerable populations to find new

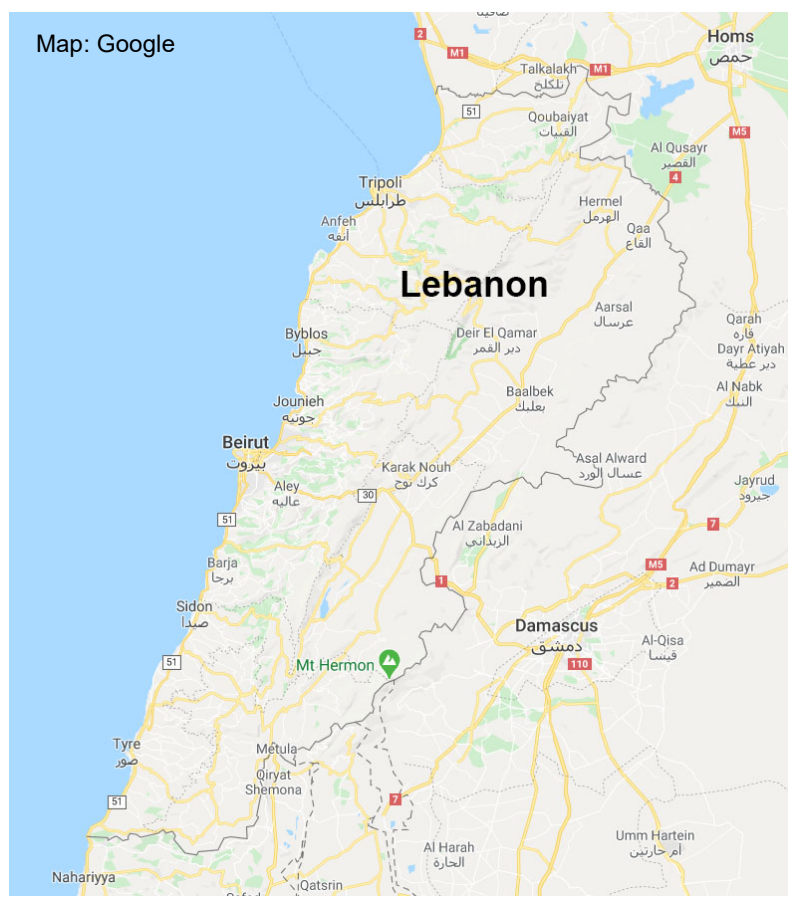
income opportunities to meet their basic needs is limited in an already highly competitive labour market, where unemployment rates are over $30 \%$ for Lebanese workers and $40 \%$ for Syrians. ${ }^{7}$ This is especially true for groups that have traditionally been marginalized (e.g. women, youth and people with disabilities) and members of extremely vulnerable households.

\section{THE MEDUP! PROJECT IN LEBANON}

The MedUP! Promoting Social Entrepreneurship in the Mediterranean Region project aims to improve the social entrepreneurship landscape in Lebanon and five other countries in the region at the macro, meso and micro levels by facilitating enabling policies, networking and capacity building for support organizations, and by directly nurturing a group of potential social enterprises. Its specific objectives include:

- At the macro level: to increase economic inclusiveness and employment in six targeted countries (Lebanon, Morocco, Tunisia, Egypt, Palestine and Jordan) by promoting country and cross-country policy and advocacy initiatives and public-private dialogue, and by creating an enabling regulatory and policy environment. 
- At the meso level: to reinforce 10-15 social entrepreneurship support organizations (SESOs) through capacity-building and networking activities.

- At the micro level: to provide financial and technical support to 1015 social enterprises (SEs) in each country. ${ }^{8}$

\section{MedUP!'s progress to date}

MedUP! has been operational in Lebanon since March 2018 and the programme will continue until March 2022. The progress it has made to date includes the following:

- Launch of a landscape study for social entrepreneurship. A country study (unpublished) was undertaken to improve understanding of the social enterprise landscape in Lebanon, anchored by Beyond Reform and Development (BRD), a missionoriented development consulting firm. The findings of the study are discussed below.

- Creation of a network of SESOs in Lebanon. Training for SESOs was held in 2018 with the aim of creating a network among the main actors in the SE ecosystem in Lebanon.

- Launch of the MedUP! Grant Fund to support and mentor SEs. A call for applications was launched with the aim of supporting existing SEs financially through cash grants and with dedicated technical coaches to support them in scaling up their businesses.

- Public-private dialogue for policy advocacy. Public-private dialogues have been initiated with several ministries, government representatives and private companies to influence actions to strengthen the regulatory framework supporting SEs in the country.

\section{STUDY TO UNDERSTAND THE SOCIAL ENTREPRENEURSHIP LANDSCAPE IN LEBANON}

A study and mapping of actors was undertaken by the MedUP! regional project, with a number of objectives:

- to inform the design of activities in the project, particularly policy-level interventions, as well as the support needed by SESOs;

- to allow for analysis and comparison of cross-regional data and experiences from the six countries involved; and

- to fill gaps in knowledge about the Lebanese SE landscape and analysis and to allow for more informed and effective interventions in the future. 


\section{Choice of BRD as a consultant, based on its experience in the development of social entrepreneurship in the Middle East}

BRD has been a key influencer in the development of the social entrepreneurship sector in the Middle East and North Africa and in Lebanon since 2010. It is a mission-driven consulting firm specializing in policy research, public management, capacity development and partnership building. It is known for its ability to bring global knowledge to the Arab context through its partnership approach and its experiential methodologies.

\section{Process of the study}

BRD had pre-existing data from a regional study it conducted in 2016 for the European Union. This was done for the formulation of a new regional programme to support social business ecosystems in the 'Southern Neighbourhood' region, covering Algeria, Morocco, Tunisia, Egypt, Jordan, Palestine and Lebanon. BRD also drew on the draft legal and policy framework for Lebanon that it has been facilitating over the past two years; the aim of this is to boost the social entrepreneurship ecosystem and create an enabling environment for SEs.

\section{BRD's contribution to the social entrepreneurship landscape}

BRD has worked on the design and implementation of numerous initiatives in the social entrepreneurship sector, with a focus on three strategic pillars:

1. Education: BRD has developed a series of programmes, curricula and toolkits in more than 15 graduate and undergraduate colleges and has disseminated them widely across a number of countries in the region.

2. Ecosystem: BRD has trained more than 10,000 people in social entrepreneurship skills and has established a number of incubators, three of which are in universities. It has conducted social entrepreneurship competitions, with more than 1,300 people submitting socially innovative ideas and taking part in 'boot camps' and incubation programmes. It has also worked with municipalities in Lebanon to promote their role as entrepreneurial incubators, and assisted them in launching local competitions for social entrepreneurship.

3. Policy research and advocacy: For the past three years, BRD has facilitated efforts towards the development of a national social entrepreneurship strategy in Lebanon to boost the SE ecosystem by formulating a social entrepreneurship policy and a legal framework, engaging more than 70 stakeholders in the process. This dialogue has also aimed to create an enabling environment and an institutionalized platform to support SEs in Lebanon.

The BRD study analysed the SE ecosystem in Lebanon and its main stakeholders, needs and constraints, as well as ongoing initiatives, with a preliminary mapping of key sectors and the characteristics of social enterprises. The mapping categorized the different support organizations 
based on the services that they provide, their sector of intervention, regional reach and whether or not they focus on SEs.

BRD undertook a data collection exercise to update and to gather necessary and relevant information. This included a series of interviews and focus groups with key stakeholders such as public institutions, the Ministry of Social Affairs, the Ministry of Economy and Trade, the private sector, support organizations, academic institutions, civil society and donors. Gaining access to stakeholders was relatively easy as BRD already had connections across the ecosystem and through projects it has previously implemented.

\section{KEY INSIGHTS ON THE SOCIAL ENTREPRENEURSHIP LANDSCAPE IN LEBANON}

\section{SEs differ in their nature, definitions and challenges}

Social entrepreneurship is defined by the BRD study as any process by which a group of citizens strive to solve their community's social problems innovatively and sustainably by using local resources to create products or services that generate revenue, with profit reinvested to scale up the social impact. There is as yet no policy or legal framework for social enterprises in Lebanon, but BRD has defined a set of parameters covering three dimensions:

- the social outcome intended by social enterprises, such as social impact and innovation within a country's political, social, economic and cultural contexts;

- the governance structure of the social enterprise, which differs from country to country based on the legal frameworks available; and

- the agency of the social enterprise (or the group) that is driving it, as this is critical for the credibility and legitimacy of the enterprise.

\section{There is no clear difference between development disciplines for social entrepreneurship and more general kinds of entrepreneurship}

In Lebanon, the social entrepreneurship field is closely intertwined with that of entrepreneurship more generally. While this allows for crossfunctional exchange, it imposes limitations in studying the social entrepreneurship ecosystem in terms of its definitions and scope. Most studies have focused on the general entrepreneurship sector and have assessed and analysed needs and challenges solely from an entrepreneurship development perspective. The interventions and 
policies of public institutions and even donor-led projects are not tailored to the needs of social entrepreneurs. This has created gaps and challenges in the understanding of the phenomenon of social entrepreneurship in Lebanon and hence its future development.

\section{There are barriers to scale}

SEs in Lebanon face different barriers, including a challenging context due to economic and political uncertainty, a limited number of ideas with the potential to be scaled up, ambiguous understandings of social entrepreneurship among citizens, weak connections between social entrepreneurs and a tendency to rush to scale up without planning.

\section{There are gaps in SESOs' existing services}

SEs have access to services, mostly at the ideation and start-up stages, but not in the growth stage. SE initiatives in Lebanon receiving support from various organizations and programmes are generally satisfied with the services they receive in the ideation and start-up phases of development. The country study shows, however, that SEs in their growth phase have more specific needs, which are rarely met within the ecosystem at present.

\begin{tabular}{|l|l|l|}
\hline $\begin{array}{l}\text { Enterprise } \\
\text { stage }\end{array}$ & $\begin{array}{l}\text { Availability } \\
\text { of services }\end{array}$ & Nature of services needed \\
\hline $\begin{array}{l}\text { Ideation } \\
\text { stage }\end{array}$ & Available & $\begin{array}{l}\text { Innovation hubs, setting up formal and non- } \\
\text { formal entrepreneurship programmes }\end{array}$ \\
\hline $\begin{array}{l}\text { Start-up } \\
\text { stage }\end{array}$ & Available & $\begin{array}{l}\text { Informal and formal mentoring, access to } \\
\text { funding institutions }\end{array}$ \\
\hline $\begin{array}{l}\text { Growth } \\
\text { stage }\end{array}$ & Missing & $\begin{array}{l}\text { Philanthropy and subsidized loans, access to } \\
\text { mentoring services }\end{array}$ \\
\hline
\end{tabular}

\section{There is no specific legal model for SEs under the existing regulatory framework}

There is no specific legal form of establishment for social enterprises in Lebanon, and so social entrepreneurs are using existing legal forms to set up their entities - either as NGOs, commercial enterprises (SARL: Societé à Responsabilité Limitée, or SAL: Societé Anonyme Libanaise), or cooperatives. In some cases, enterprises choose to combine models and to register as both a SAL and an NGO, under the same name. This allows them to direct their social impact activities through the NGO structure, while their revenue-generating activities are channelled through the commercial entity. It is important to note that fewer start-ups opt to establish themselves as cooperatives. This is because, in practice, cooperatives are now mainly limited to agricultural activities and face many bureaucratic procedures under the Ministry of Agriculture. Many SEs are registering as 'civil companies', which is a legal form applicable to service companies as opposed to manufacturing companies, and is used mainly for law firms, private health clinics and small consulting firms. 


\section{The ecosystem is crowded}

A large number of organizations offer different types of support to entrepreneurs and social entrepreneurs. The quality of support is affected by the variety of definitions of concepts that exist and sometimes by the interchanging and overlapping mandates of organizations. This was apparent from the study: it was difficult to identify organizations as relevant service providers for the social entrepreneurship sector. This is mainly because many support organizations, even public entities, either do not distinguish between social entrepreneurship and entrepreneurship more generally or offer standard support to all.

\section{A coordination platform is needed for SESOs}

A key gap in the ecosystem is a lack of coordination, and so a platform needs to be created where SESOs can interact and learn from each other, while also hearing from social entrepreneurs about their needs and requests. Oxfam might be able to contribute here.

\section{There is a risk of donor dependency}

Many initiatives and organizations are either led or influenced by support from donors, which both distorts the SE ecosystem and its support organizations by keeping them under the influence of external actors, and increases their dependency on donor funding. This makes their business models vulnerable.

\section{The regulatory framework is weak}

Lebanon lacks a clear public policy on social entrepreneurship. The absence of an overall policy and a legal framework does little to encourage social entrepreneurs, who lack incentives.

\section{LESSONS LEARNED FOR}

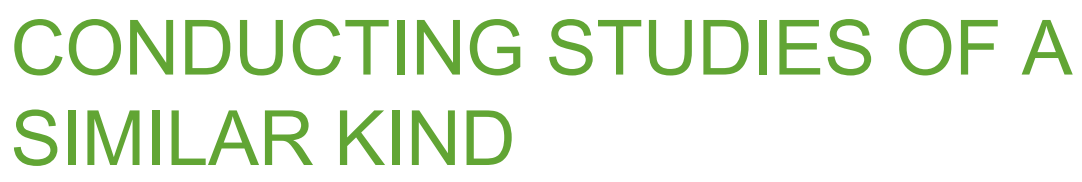

- The research for this study and its findings implicitly target actors with capacities and stakes in advocating for policy changes and development opportunities for social entrepreneurship. These stakeholders had very limited involvement in the study itself, for different reasons. In future, for similar exercises, it is essential to identify key influencers and to engage them in the study from the beginning.

- In Lebanon, reluctance on the part of public institutions and their representatives to get involved is a major challenge, owing to the absence of any public policy on social entrepreneurship. 
- Social entrepreneurs and their support organizations face similar challenges. Until recently, there has been no entity uniting SEs in order to pursue common goals, and most SEs and support organizations are unable to allocate the time needed for advocacy and research work. A new organization, the Lebanese Social Enterprises Association (LSE), has been established very recently, but it is still in the process of setting up and has not officially begun working in Lebanon. $^{9}$

\section{NOTES}

1 EDS. (2018). The Crisis Economy in Lebanon: Winners and Losers. Commissioned by Oxfam on behalf of the LEADERS Consortium; unpublished. The LEADERS consortium was established in Jordan and Lebanon by five major INGOs, including the Danish Refugee Council (DRC), Oxfam, CARE, ACTED and Save the Children. The collective aim of the consortium is to improve the capacity and quality of the response and to address the resilience and livelihood needs of Syrian refugees and host communities in the countries neighbouring Syria, with a specific focus on Lebanon and Jordan. On 1 June 2016, the EU Regional Trust Fund in Response to the Syrian Crisis (the 'Madad' Fund) awarded funding to the LEADERS consortium with DRC as lead applicant, covering both Jordan and Lebanon.

2 LEADERS Consortium. (2017). Dignity at Stake: Challenges to Accessing Decent Work in Lebanon. https://reliefweb.int/sites/reliefweb.int/files/resources/69774.pdf

3 Government of Lebanon and the United Nations. (2019). Lebanon Crisis Response Plan 2017-2020. https://reliefweb.int/sites/reliefweb.int/files/resources/67780.pdf

4 lbid.

5 The rate of informal employment was estimated at $50 \%$ by the World Bank in 2012. World Bank. (2012). Republic of Lebanon: Good Jobs Needed: The Role of Macro, Investment, Education, Labor, and Social Protection Policies ("Miles"), p.1. http://documents.worldbank.org/curated/en/230521468089355499/pdf/760080ESW0 GRAY0C0Disclosed030200130.pdf. The Government of Lebanon stated in its Vision for Stabilization, Growth and Employment, presented at the Brussels Conference in April 2017: 'The World Bank estimates that as a result of the Syria crisis some 200,000 Lebanese have been pushed into poverty (adding to the 1 million before the crisis) and that some 250,000-300,000 have become unemployed, in particular youth, with the overall unemployment rate doubling to about $20 \%$. Unemployment among Lebanese youth stands at $30 \%$ according to UNICEF and is attributed in part to displacement by Syrian workers who accept lower wages.' http://www.cdr.gov.lb/study/cedre/CedreGoLVisionMarch15.pdf

6 World Bank. (2013). Enterprise Survey: Lebanon. https://www.enterprisesurveys.org/en/data/exploreeconomies/2013/lebanon\#2

7 Government of Lebanon and the United Nations. (2019). Lebanon Crisis Response Plan 2017-2020, op. cit.

8 For more information on the MedUP! programme, see: https://www.oxfamitalia.org/medup/

9 For more information, see: http://www.Iseassociation.org/ 


\section{OXFAM}

Oxfam is an international confederation of 20 organizations networked together in more than 90 countries, as part of a global movement for change, to build a future free from the injustice of poverty. Please write to any of the agencies for further information, or visit www.oxfam.org 